\title{
Penerapan Internet of Things (IoT) pada Perangkat
}

\section{Phototherapy}

\author{
Royan $^{1}$, Kusnanto Mukti wibowo ${ }^{2}$, Gema Romadhona ${ }^{3}$, dan Anang Widiantoro ${ }^{4}$ \\ 1,2,3 Teknik Rekayasa Elektromedis, Universitas Muhammadiyah Purwokerto (UMP) \\ J1. KH. Ahmad Dahlan, PO BOX 202 Purwokerto 53182 Kembaran, Banyumas, Jawa Tengah \\ ${ }^{4}$ Teknik Elektro, Universitas Muhammadiyah Surabaya \\ J1. Raya Sutorejo No.59, Dukuh Sutorejo, Kec. Mulyorejo, Kota Surabaya, Jawa Timur 60113 \\ Email: royan@ump.ac.id
}

\begin{abstract}
Abstrak - Phototherapy merupakan perangkat yang dapat menghasilkan radiasi cahaya biru untuk terapi hiperbilirubinemi. Phototherapy memiliki banyak jenis lampu yang dapat menghasilkan radiasi sinar biru,salah satunya neon tabung yang banyak kita jumpai di indonesia, jenis lampu ini harganya murah namun masa efektifnya pendek, sehingga untuk meningkatkan efektivitas terapi hiperbilirubinemia, lampu harus di ganti ketika nilai iridiasinya kurang dari $176 \mu \mathrm{W} / \mathrm{cm}^{2}$ atau sekitar 2000 jam penggunaan. Tujuan dari penelitian ini adalah mengembangkan phototherapy yang dilengkapi dengan notifikasi via smartphone, sehingga sebelum masa efektif lampu habis, phototherapy secara otomatis mengirimkan pesan singkat kepada pengguna. Berdasarkan pengujian dengan perbandingan waktu 1:100, pengguna menerima pesan singkat 3 menit sebelum masa efektif lampu habis, Notifikasi ini sangat membantu manajemen rumah sakit untuk menganggarkan pembelian suku cadang.
\end{abstract}

Kata kunci : Phototherapy, Hiperbilirubinemi, Radiasi Cahaya Biru

\begin{abstract}
Phototherapy has many types of lights that can produce blue light radiation, one of which is fluorescent tubes that we have encountered in Indonesia, this type of lamp is cheap but its effectiveness is short, to increase the effectiveness of hyperbilirubinemia therapy, the lamp must be replaced when the iridium's value is less than $176 \mu \mathrm{W} /$ $\mathrm{cm}^{2}$ or about 2000 hours of use. The purpose of this study is to develop phototherapy which is equipped with a notification via smartphone so that before the effective period of the lamp runs out, phototherapy automatically sends a short message to the user. Based on testing with a time ratio of 1: 100, users receive a short message 1 minute before the effective time of the lights out, this notification is very helpful for hospital management to budget for the purchase of spare parts.
\end{abstract}

Keywords: Phototherapy, Hiperbilirubinemi, Blue Light Radiation

\section{PENDAHULUAN}

Fenomena klinis yang sering terjadi pada bayi yang usianya kurang dari satu minggu adalah hiperbilirubinemia, dalam penelitian yang dilakukan oleh Alini dan Rasydah Mahmud [1], terdapat $85 \%$ bayi yang baru lahir terkena hiperbilirubinemia. Hal ini dikarenakan pada minggu pertama produksi bilirubin bayi meningkat,sedangkan organ hati pada bayi terkadang belum mampu mengatasinya. Bilirubin yang tidak dapat dikeluarkan dari dalam tubuh kemudian berkumpul dijaringan bawah kulit, sehingga menimbulkan warna kuning pada kulit yang disebut Hiperbilirubin.

Hiperbilirubinemia adalah keadaan kadar bilirubin dalam darah $>13 \mathrm{mg} / \mathrm{dL}$. hiperbilirubinemia dapat menekan konsumsi oksigen $\left(\mathrm{O}^{2}\right)$, oksidasi fosforilasi yang menyebabkan kerusakan sel-sel otak dan mengakibatkan disfungsi neuronal, Bayi dengan keadaan tersebut berisiko mengalami kecacatan bahkan kematian [2]

Phototherapy merupakan salah satu cara untuk pengobatan hiperbilirubinemia pada neonatus dengan memanfaatkan energi sinar biru, phototherapy dapat mengubah bentuk dan struktur bilirubin,mengubah bilirubin indirek menjadi direk sehingga dapat terikat oleh makanan menjadi molekul yang dapat dieksresikan melalui feses [3].

Phototherapy jenis neon tabung masih banyak digunakan di Indonesia, Jenis lampu ini mudah diperoleh dan harganya terjangkau, namun usia pakainya pendek, sehingga untuk meningkatkan efektivitas terapi, neon tabung harus diganti ketika nilai iradiasi kurang dari $176 \mu \mathrm{W} / \mathrm{cm}^{2}$ atau sekitar 2000 jam penggunaan [4].

Di era kemajuan teknologi, sebuah inovasi baru dapat diciptakan dengan menerapkan konsep internet of things (IoT), seperti penelitian yang dilakukan oleh David Setiadi dan Muhamad Nurdin Abdul Muhaemin [5]. Mereka menerapkan IoT untuk monitoring irigasi, selanjutnya Aulia Faqih Rifa'I [6]. Dia menerapkan IoT untuk memonitor kebocoran gas. IoT juga banyak di aplikasikan dalam bidang kesehatan, seperti penelitian yang dilakukan oleh Jorge Gomeza, Byron Oviedob dan Emilio Zhumab [7]. Mereka menerapkan IoT untuk sistem pasien monitor. Penelitian serupa juga dilakukan oleh Shivam Gupta dan kawan-kawan [8].

Dari latar belakang di atas, penulis merancang sebuah perangkat Phototherapy yang dilengkapi dengan hour meter 
untuk menghitung jam pemakaian neon tabung, dan di lengkapi dengan notifikasi melalui smartphone, sehingga massa efektif neon tabung dapat diinformasikan melalui pesan singkat.

\section{Metode}

Penelitian ini menggunakan hour meter dengan perbandingan 1:100 terhadap waktu nyata, sehingga notifikasi akan dikirimkan 3 menit sebelum masa efektif neon tabung habis, yang mewakili 300 jam.

A. Alat dan Bahan

Penelitian ini menggunakan mikrokontroler ATMega8535 dan ESP8266. ATMega8535 digunakan sebagai counter yang menghitung jam pemakaian phototherapy dan menyimpanya dalam memori internal, sehingga data tidak hilang ketika power dimatikan, ATMega8535 juga akan mengirimkan informasi terkait masa efektif lampu yang segera berakhir ke ESP8266. Selanjutnya informasi yang diterima oleh ESP8266 akan diteruskan ke pengguna melalui smartphone dengan aplikasi blynk.

\section{B. Line Diagram}

Dalam penelitian ini, rancangan phototherapy secara keseluruhan diperlihatkan pada gambar 1 .

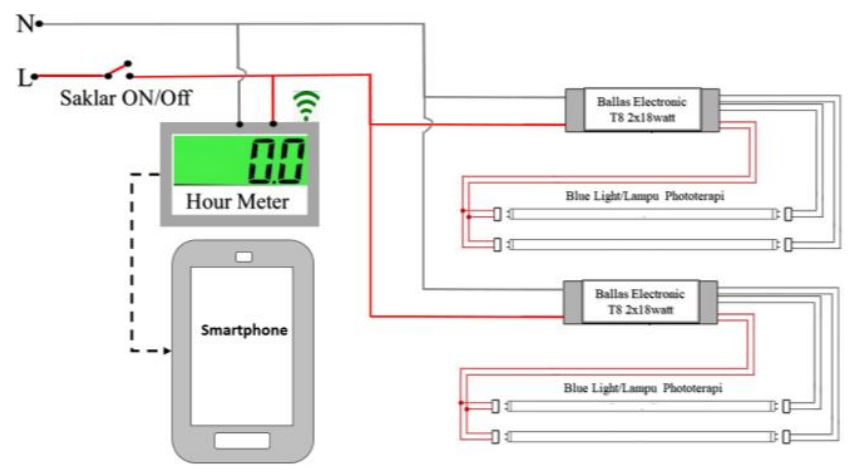

Gambar 1. Line diagram phototherapy

Gambar 1 menunjukan prinsip kerja phototherapy secara keseluruhan, ketika saklar dihidupkan maka lampu blue light menyala dan hour meter mulai menghitung, kemudian ketika hour meter mencapai 1700 jam, secara otomatis hour meter akan mengirimkan pesan singkat melalui smartphone.

\section{Rangkaian skematik Hour meter}

Bagian terpenting dari pengembangan phototherapy ini adalah rangkaian mikrokontroler ATMega8535 dan ESP8266 seperti yang diperlihatkan pada gambar 2.

ATMega8535 berfungsi untuk menghitung pemakaian phototherapy dan mengakumulasi pemakaian berikutnya, data disimpan di dalam memori internal, sehingga data tidak hilang meskipun catu daya dimatikan, selain itu ATMega8535 juga menampilkan data kedalam display LCD dan memberikan kode digital ke ESP8266 ketika masa efektif blue light hampir habis, kemudian kode digital yang diterima oleh ESP8266 akan diterjemahkan sebagai notifikasi masa efektif blue light yang hampir habis dan dikirimkan ke smartphone melalui internet.

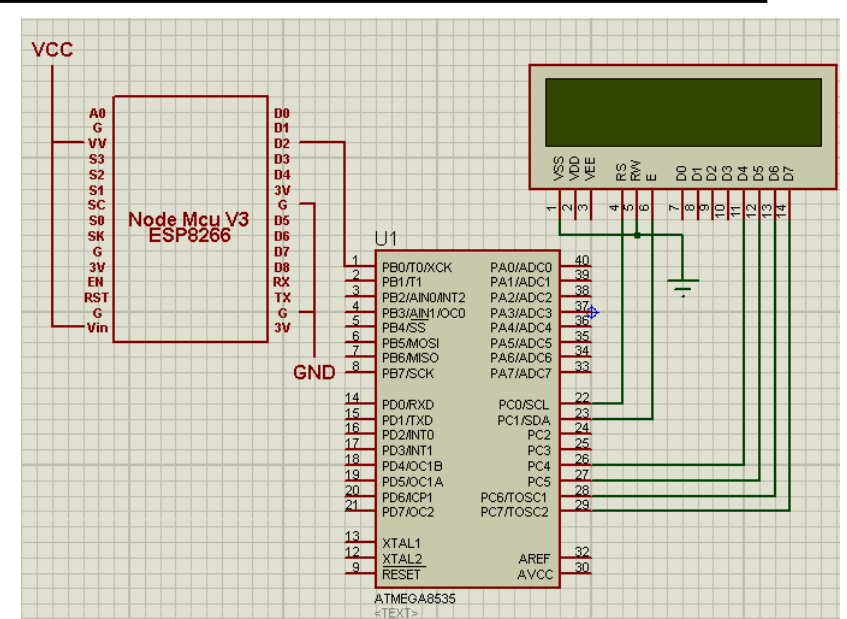

Gambar 2. Rangkaian hour meter phototherapy

\section{HASIL DAN PEMBAHASAN}

Dalam penelitian ini, phototherapy berhasil di rancang dan di uji. Hasilnya menunjukan bahwa phototherapy layak untuk di produksi secara profesional. Hasil rancangan phototherapy diperlihatkan pada gambar 3 .

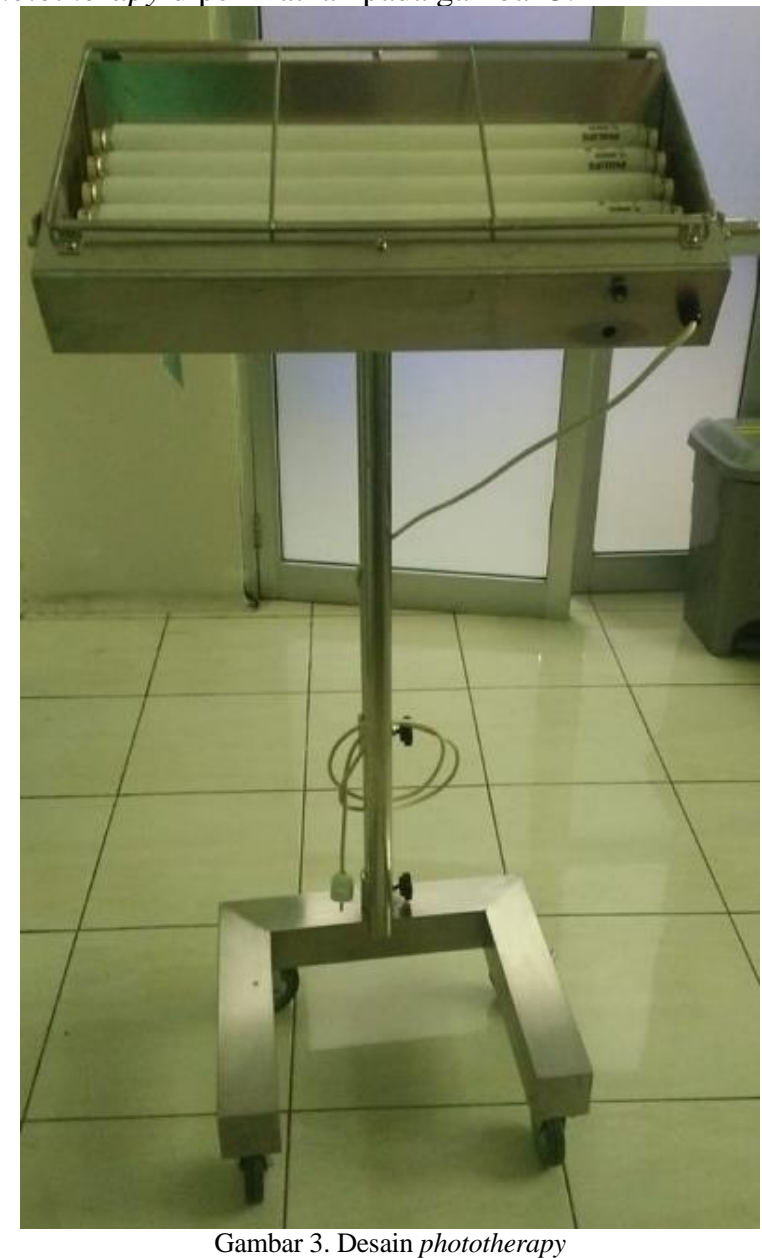

Gambar 3 menunjukan hasil rancangan phototherapy yang terdiri dari 4 buah lampu blue light. Unjuk kerja phototherapy di perlihatkan pada gambar 4 . 


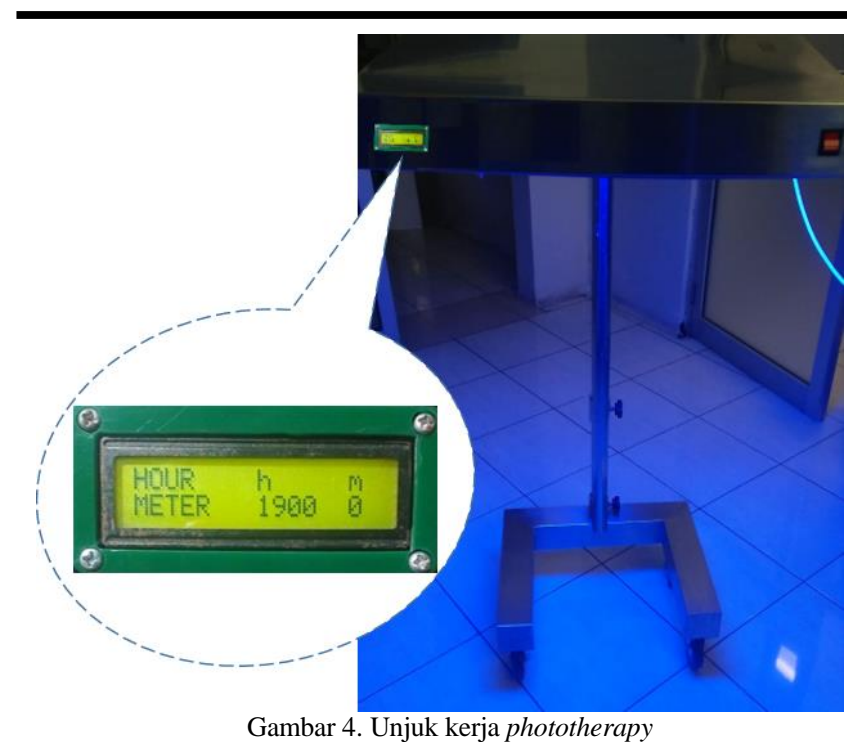

Gambar 4 menunjukan unjuk kerja blue light, ketika saklar di hidupkan, lampu blue light menyala dan hour meter menghitung jam pemakaianya, kelebihan dari houre meter ini adalah secara otomatis akan mengirimkan pesan singkat ketika masa efektif blue light mendekati habis, pesan singkat yang di kirimkan ke smartphone diperlihatkan pada gambar 5 .

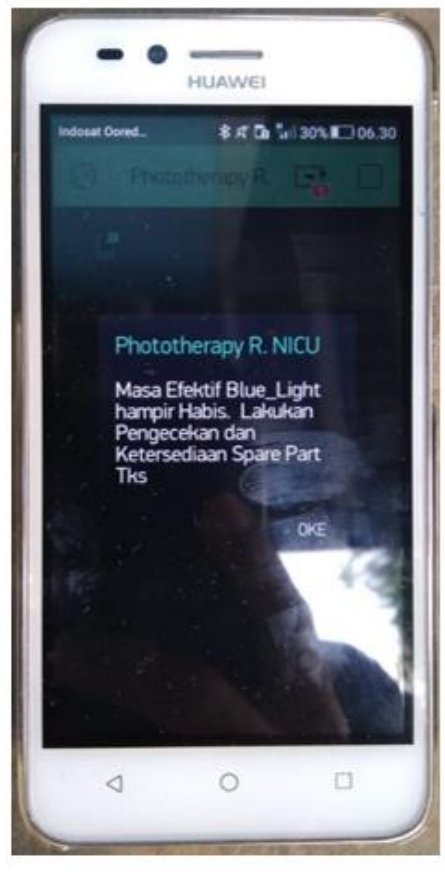

Gambar 5. Notifikasi dari phototherapy

\section{A. Desain perangkat lunak}

Dalam penelitian ini, perangkat lunak terdiri dari dua buah program, diantaranya bascomAVR dan arduino IDE. bascomAVR untuk memprogram ATMega8535 sebagai counter dari hourmeter phototherapy dan program arduino IDE untuk memprogram ESP8266 sebagai modul yang berfungsi untuk interface dengan internet sehingga notifikasi dapat dikirimkan melalui smartphone.

1. Listing Program Bascom AVR

Listing program 1.Program counter dan display \$crystal $=16000000$

\$eeprom

'konfigurasi LCD

Config Lcdpin $=$ Pin , Rs = Portc. $3, \mathrm{E}=$ Portc. $2, \mathrm{Db} 4$ $=$ Portc .4, Db5 $=$ Portc .5, Db6 $=$ Portc. 6, Db7 $=$ Portc. 7

Config Lcd $=16 * 2$

Cursor Off

Cls

Dim Jam As Integer, Menit As Byte

Dim Simpan As Eram Integer

'Program utama

Do

Incr Menit

Waitms 10' // perbaindingan 1:100 (untuk 1detik)

If Menit > 59 Then

Menit $=0$

Incr Jam

End If

'notifikasi di kirim setelah 1900 (1:100)

If Jam = 19 And Menit $=0$ Then

Gosub Kirim_notifikasi_esp8266

End If

'tombol rahasia untuk reset hourmeter setelah penggantian blue light

If Pinb. $0=0$ Then

'Jam $=0$

'Menit $=0$

End If

' data di simpan di memori internal dan di akumulasi '-

Writeeeprom Jam

Readeeprom Jam

Locate 1,1

Lcd "HOUR h m"

Locate 2,1

Lcd "METER";jam;menit

Loop

Kirim_notifikasi_esp8266:

Pinb. $1=1$

Waitms 200

Pinb. $1=0$

Return 
2. Listing program arduino

Listing program 2. Program notifikasi via smartphone

\#include <ESP8266WiFi.h>
\#define BLYNK_PRINT Serial
\#include <BlynkSimpleEsp8266.h>
charauth[]="KWJ_AVik_JoBondlJ7LjdoUkAuMV7f
yy";
\#define inputATMega8535 D2
char ssid[] = "Net1-Royan abu zian";
char pass[] = "87654321";
volatile bool inputATMega8535Flag = false;
int IO;
void setup()
\{
Serial.begin(115200);
delay(10);
Blynk.begin(auth, ssid, pass);
pinMode(inputATMega8535, INPUT);
\}
void loop() \{
IO = digitalRead(inputATMega8535);
if(IO==HIGH)\{
while(IO=digitalRead(inputATMega8535)); //nunggu
kode digital di kirim oleh ATMega8535
Blynk.notify("Masa Efektif Blue_Light hampir Habis.
Lakukan Pengecekan dan Ketersediaan Spare PartTks
");
delay(500);
$\quad$

B. Nilai kesalahan Hour meter dalam mengirimkan pesan singkat

Hasil pengujian hour meter pada phototherapy dibandingkan dengan stopwatch. Nilai kesalahan ditampilkan pada Tabel 1.

Tabel 1. Hasil pengujian houre meter pada phototherapy dibandingkan dengan stopwatch

\begin{tabular}{cccc}
\hline Pengujian & $\begin{array}{c}\text { Pembacaan } \\
\text { Hour meter } \\
\text { (menit) }\end{array}$ & $\begin{array}{c}\text { Pembacaan } \\
\text { stopwatch } \\
\text { (menit) }\end{array}$ & $\begin{array}{c}\text { Error } \\
\%\end{array}$ \\
\hline 1 & 17 & 17.38 & 2.2 \\
2 & 17 & 17.30 & 1.7 \\
3 & 17 & 17.33 & 1.9 \\
4 & 17 & 17.37 & 2.1 \\
5 & 17 & 17.34 & 2 \\
\hline
\end{tabular}

Dari hasil pengujian yang diperlihatkan pada Tabel 1, hour meter hasil rancangan memiliki nilai kesalahan rata-rata $1.98 \%$ sehingga pesan singkat yang dikirimkan melalui smartphone terlambat $1.98 \%$ dari waktu yang sebenarnya.

\section{KESIMPULAN}

Pada penelitian ini phototherapy yang di lengkapi dengan notifikasi via smartphone telah berhasil di buat. hour meter dapat mengakumulasi waktu pemakaian, serta dapat mengirimkan notifikasi ketika masa efektif blue light mendekati habis, namun masih mengalami keterlambatan dalam proses mengirimkan pesan singkat sebesar $1.98 \%$ dari waktu sebenarnya, hal ini dipengaruhi oleh timer internal dari mikrokontroler ATMega8535 yang tidak stabil.

\section{REFERENSI}

[1] Alini, M.Rasydah,"Hubungan pemasangan blue ligh therapy dengan kecemasan ibu di ruang perinatologi Rsud puri husada tembilahan"Jurnal Ners Universitas Pahlawan,Volume 3 Halaman 1 $-6,2019$.

[2] N.W.Wikanthiningtyas, S.Mulyanti,'Pengaruh alih baring selama fototerapi terhadap perubahan kadar bilirubin pada ikterus neonatorum Di ruang hcu neonatus rsud dr. Moewardi'Jurnal Keperawatan Global, Volume 1, No1, hlm 01-54, Juni 2016

[3] F.Yuliawati, N.L.P.E.Sudiwati, Lastri "Studi Komparatif Kadar Bilirubin Pada Bayi Baru Lahir Dengan Fototerapi Yang Diberikan Asi Esklusif Dan Non Esklusif Di Rst Malang”Nursing News Volume 3, Nomor 1, 2018

[4] G.H.Purnomo, B.Utomo, T.Rahmawati, "Phototeraphy Radiometer Dengan Penyimpanan Data Pengukuran Pada SDCard," pp. 1-7, 2018.

[5] D.Setiadi,M.N.A.Muhaemin"Penerapan internet of things(IoT) pada sistem monitoring irigasi'Jurnal Infotronik Volume 3, No. 2, Desember 2018

[6] A.F.Rifai"Sistem Pendeteksi Dan Monitoring Kebocoran Gas (Liquefied Petrolum Gas) Berbasis Internet Of Things 'JISKa, Vol. 1, No. 1, MEI, 2016

[7] J.Gomes, B.Oviedo,E.Zhuma"Patient Monitoring System Based on Internet of Things"Procedia Computer Science 83, ) 90 - 97, 2016

[8] S.Gupta, S.Kashaudhan, D.C.Pandey, P.P.S.Gaur'IOT based Patient Health Monitoring System 'International Research Journal of Engineering and Technology (IRJET),Volume: 04 Issue: 03 ,Mar 2017 